\title{
THE STORYBOARD DEVELOPMENT OF VIRTUAL REALITY SIMULATION (VRS) OF NURSING CARE IN RESPIRATORY SYSTEM DISORDERS COURSE
}

\author{
Ryan Hara Permana ${ }^{1 *}$, Mira Suryani ${ }^{2}$, Dian Adiningsih ${ }^{3}$, Erick Paulus ${ }^{4}$ \\ ${ }^{1,2,3,4}$ Faculty of Nursing Universitas padjajaran \\ Email*: ryan.hara@unpad.ac.id
}

\begin{abstract}
Introduction :Practicingclinical nursing skills requires high fidelity learning methods but are often constrained by financial factors. Virtual Reality Simulation (VRS) is a practical learning method that is able to project visually the experience of practicing nursing care in a virtually real situation. VRS is financially affordable and portable, allowing students to learn whenever and wherever. This study focused on developing the storyboard of a VRS as a method of practicing nursing care skills in the case of acute respiratory system infection at Faculty of Nursing, Universitas Padjadjaran. Methods: This study utilized qualitative descriptive design.An expert group consists of a paediatric nurse, a senior paediatric nursing lecturer, an e-learning expert and two VR experts was working serially to develop the case and storyboard. The case development stage was conducted using a Focus Group Discussion (FGD) and the storyboard development stage used two workshop sessions. The NLN/Jeffries Simulation was used as a framework to develop the storyboard. Results: The learning objectives, scenes, actions, challenges and redirect elements were identified. The learning objectives is the most essential foundation in building a storyboard. Conclusion: The storyboard template allows subject matter experts to develop VRS that capable to train nursing care skills in a safe and immersive environment.
\end{abstract}

Keywords: Learning Methods, Nursing Care, Nursing Education, Virtual Reality Simulation (VRS).

\section{INTRODUCTION}

The quality of learning in nursing education is influenced by the quality of the learning method (Gaberson \& Oermann, 2010). Laboratory practice is the main method that can facilitate the learning of nursing care skills including cognitive, affective and psychomotor domain, comprehensively (Boore, Cook, \& Shepherd, 2016). Students will have authentic learning experience in performing nursing care for patients.

The ideal practicum method needs to be supported by high-fidelity learning media and good instructional design (Munshi, Lababidi, \&Alyousef, 2015). Learning media with high-fidelity categories are the one that can provide authentic learning experiences that are almost similar to the actual environment (Jeffries \& Jeffries, 2012). This learning media will help nursing students achieve their learning outcomes so that it will have an impact on the quality of the clinical nursing skills they acquired as professional nurses.

However, the application of high fidelity practicum facilities is generally quite expensive and requires large resources to manage them (Meyer, Innes, Stomski,
\&Armson, 2016). So, currently to teach clinical nursing skills, practicum is generally carried out in nursing laboratories using lowfidelity mannequins.

One the the recommended learning method for practicing clinical nursing skills is Virtual Reality Simulation (VRS) (Bouamrane \& Mair, 2014; Jenson \& Forsyth, 2012; LundeHusebø \& Storm, 2014; Ma, Jain, \& Anderson, 2014). VRS is a computer program that makes images and objects appear real by projecting a three-dimensional (3-D) display and using stereo images to give a sense of real presence, which is the feeling of being in a simulated environment. The VRS environment has the ability to reproduce a clinical environment where users can interact with patients and virtual resources and practice content as often as needed.

Globally, the use of Virtual Reality Simulation (VRS) technology is growing rapidly in academic and health care areas (Alexander, Pasupathy, Steege, Strecker, \& Carley, 2014). This computer-based threedimensional educational tool enables procedural practice in a safe virtual environment. VRS allows lecturers to provide 
fast feedback for students, and is useful in reducing the risk of errors in nurse practice, so that the expected learning outcomes. VRS allows repetitive and portable training sessions VRS is also considered a more financially affordable method for nursing education institutions (Ma et al., 2014).

However, the implementation of VRS in nursing education in Indonesia is still limited and there is no VRS technology specifically designed for nursing education in Indonesian settings and languages. Therefore, it is necessary to conduct research and development of Virtual Reality Simulation (VRS) specifically designed for nursing area in Indonesia. This study aims to develop a Virtual Reality Simulation (VRS) storyboard with a case of nursing care in a patient with respiratory system disorder in the laboratory of the Faculty of Nursing, Universitas Padjadjaran.

\section{Virtual Reality Simulation (VRS) Padjadjaran}

Virtual Reality (VR) is a technology that uses computerized displays to model real life environments where users can interact as usual (Davis, 2009). Real-life environmental models in the form of 3D worlds made as closely as possible. VR technology allows users to interact using head movements, eye movements, joysticks, hand and foot movements.In its implementation, VR has penetrated into various fields such as media, communication, travel, education (Paulus, Suryani, Farabi, Yulita, \&Pradana, 2016), games, medical (Parsons et al., 2017), and the military (Park, 2017).

In nursing education, VR technology is an alternative in providing simulation-based training. iThe use of VR in nursing education is ideally suited to measuring various variables related to nursing skills such as complex cognitive thinking abilities (such as navigation, learning and remembering, and spatial learning), social, and psychomotor aspects measured both individually and in groups (Davis, 2009). The results of VR implementation in the nursing teaching and learning process also significantly improve the performance of learners (Foronda et al., 2017). This is supported by the excellence of VR technology that supports constructivism theory by focusing learning activities from learners interactively so as to enable minimizing the gap between student knowledge and real experience (Huang \&Liaw, 2018). In addition, VR for nursing education can also be used to train clinical reasoning skills (ZacharzukMarciano, 2017).

VRS Padjadjaran is an integration of VR technology in nursing simulation. The type of VRS in this case is immersive VR (Bamodu and Ye, 2013), that was built to facilitate student to practice nursing process including conducting assessment, analysing data, making nursing diagnosis, selecting intervention and making documentation. The user will feel as if he is a nurse who work in a Pusat Kesehatan Masyarakat (Puskesmas) who will be challenged to deliver nursing care for a kid with Acute Respiratory Infection (ARI). The user can use the VRS Padjadjaran Apps installed in a smartphone, a Head Mounted Devices (HMD) and a joystick to interact with the $3 \mathrm{D}$ environment that was developed with very good effect in giving the impression of a real Puskesmas room.

\section{METHODS}

This study used a research and development approach, because it aims to produce a product that is Virtual Reality Simulation learning technology (Sugiyono, 2010). The variable in this research and development was thestoryboard of Virtual Reality Simulation (VRS). The instrument used in this study were: guidelines and questions used in the FGDs and workshops. There was no invasive action in this study so there was little risk of physical injury to the respondent. The confidentiality was guaranteed and the participation of respondents in this study is voluntary.

The storyboard and case were developed in workshops using The NLN / Jeffries Simulation Framework (Jeffries, Rodgers, \& Adamson, 2016). The storyboard template was adapted from the research of Farra et al., (2016). The components of VRS storyboarding are learning objectives, scenes, actions, challenges, redirections and debriefing.

\section{RESULTS}

A. The Requirement Analysis for the Use of VRS 
The development of the storyboard and the case is a part of the VRS prototype development stage. The Subject Matter Experts (SME) or expert lecturers in basic nursing courses, nursing education curriculum development experts, and nursing education technology experts worked together to identify VRS criteria needed by nursing lecturers, including itsfunctionality as an immersive learning method, and experience. The Virtual Reality Simulation (VRS) needed by the nursing faculty has the following criteria:

1. Capable to accommodate high level learning outcomes

2. Capable to provide experiences in the form of virtual situations where students can exercise critical thinking skills and take clinical decisions with limited time (time pressured).

3. Capable to provide a safe learning environment for students to experiment and learn from mistakes.

4. Able to provide opportunities for students to analyze data and determine diagnoses and nursing interventions.

5. Able to provide a simulation of the implementation of nursing documentation

6. Provide reflective practice experience in debriefing sessions.

\section{B. The Case Development}

The case was developed in an FDG session by an expert team consists ofa paediatrician specialist nurse, a senior paediatric nursing lecturer, and an e-learning expert. The case was developed based on the learning objectives that have been prepared. The results of the case development included the subjects, structured signs and symptoms, place settings, types of examinations, nursing diagnoses and interventions. All of these items were arranged in accordance with the real conditions in the nursing practice area, so that the case is able to provide real experience that similar with the clinical nursing conditions.

The selection of subjects or patients and families in the VRS case was based on clinical conditions that Acute Respiratory Infection (ARI) usually occurs in children with the age of $\leq 10$ months who are still susceptible to respiratory infections. Usually the risk of to have ARI is also greater in children who often had choke. Underfive years old patients were not selected because they are not in accordance with clinical conditions that toddlers usually have no threatening ARI but other respiratory diseases such as respiratory tract asthma and allergies(Hockenberry \& Wilson, 2014).In addition, the expert team suggested Integrated Management of Childhood Illness (IMCI) as the guidance for the nursing care in this scenario.

The setting of the chosen place is community health centre or Puskesmas because it is a primary health facility where nurses can legally carry out nursing care for ARI patients. The room that needs to be displayed in the VRS case is the emergency room, and the nurse station. Nursing diagnosis in this case is based on NANDA 2018-2020, namely 1) cleaning of the airway is not effective associated with respiratory tract infections; and 2) hyperthermia associated with infection (Herdman\&Kamitsuru, 2017). Interventions that must be done based on the Nursing Intervention Classification (NIC) are nebulizer and oxygenation interventions (Butcher, Bulechek, Dochterman, \& Wagner, 2018; Moorhead, Johnson, Maas, \& Swanson, 2018). Signs and symptoms, clues and rationalization for VRS case are shown in Table 1.

Table 1. Signs and symptoms, instructions/clues and rationalization for VRS cases

\begin{tabular}{|c|c|c|}
\hline No & Clues & Rationalization \\
\hline 1. & $\begin{array}{l}\text { There is no family } \\
\text { history with an old } \\
\text { cough. }\end{array}$ & $\begin{array}{l}\text { To eliminate } \\
\text { TB diagnosis }\end{array}$ \\
\hline 2. & $\begin{array}{l}\text { His grandfather is an } \\
\text { active smoker }\end{array}$ & $\begin{array}{l}\text { As a } \\
\text { precipitating } \\
\text { factor for ARI }\end{array}$ \\
\hline 3. & Grunting & $\begin{array}{l}\text { Sign } \\
\text { difficulty } \\
\text { breathing }\end{array}$ \\
\hline 4 & $\begin{array}{l}\text { Dispnea since } 3 \text { days } \\
\text { ago }\end{array}$ & $\begin{array}{l}\text { Symptoms of } \\
\text { ARI }\end{array}$ \\
\hline 5 & $\begin{array}{l}\text { High fever, coughing, } \\
\text { snot, and appear pale } \\
\text { especially when } \\
\text { congested. }\end{array}$ & $\begin{array}{l}\text { Symptoms of } \\
\text { ARI }\end{array}$ \\
\hline 6. & $\mathrm{RR}=60$ times per & Data for the \\
\hline
\end{tabular}




\begin{tabular}{l} 
minute, temperature $=$ problem of \\
$39.5^{\circ} \mathrm{C}$, pulse $=121$ disruption of \\
times I minute, $\mathrm{O}_{2}$ airway \\
saturation = 95\%, clearance is not \\
child looks tight, there effective \\
is substernal and \\
intercostal retraction, \\
nasal lobe breathing, \\
there is grunting \\
sound, and sweating. \\
\hline
\end{tabular}

C. The Platforms

The storyboard is used as a communication medium between the designer and the developer team so that the design can be precisely translated by the developer team in developing the VRS. The software used in the development process is Blender software to build 3D and Unity assets for interaction development to form a VRS application. This developed VRS application can later run on the Android platform and can be displayed on the monitor screen.

\section{The Virtual Reality Simulation (VRS)Storyboard}

After learning objectives are formed, a team of experts develops the VRS scenario. VRS storyboard developed by the research team is assisted by a team of experts consisting of information technology experts, nursing education technology, and child and physiology nursing experts from Universitas Padjadjaran. The storyboard consists of two sessions: session 1 focuses on nursing assessment, and session 2 provides the experience of students to do diagnosis, intervention and nursing documentation. Students will be required to do nursing care in patients with respiratory system disorders, namely Acute Respiratory Infection (ARI). After completing all these VRS sessions students will get feedback in the form of the average value of the performance of nursing care implementation with a range of 0-100.

To provide a high level of fidelity of the scenario, the expert team conducted an FGD to discuss the possible scenarios that could occur in the cases of ARI in children (Jeffries, Rodgers, \& Adamson, 2016). The role of the user in VRS is as a nurse at a Puskesmas. The storyboard format is presented in Table 2. This format helps instructional designers in developing scenarios, to ensure that all parts of the content are developed consistently based on learning objectives. The storyboard and scenario compilation framework of Jeffries et al., (2016) includes learning objectives, scenes, actions, challenges, redirections and debriefing.

\section{E. Learning Objectives}

The expert team recommended that VRS be designed as a simulation learning medium that serves to provide a situation for students to apply the theory and concepts of anatomy, physiology, pathophysiology and nursing process in a case. This recommendation is based on the theory of constructivism where learning is formed from the understanding of students after gaining experience (Huang \&Liaw, 2018). Learning objectives are composed of learning outcomes that refer to the AIPNI curriculum and the Faculty of Nursing curriculum, particularly in the competency in providing nursing care to children with acute respiratory tract infection (ARI). Learning objectives for this VRS are: After completing simulation sessions with VRS, students are expected to be able to:

\section{Knowledge and skills}

a. Recognize signs and symptoms of ARI

b. Use therapeutic communication in nursing care

c. Conduct focus assessmenton a patient with ARI

d. Analyzing the anatomical, physiological and pathophysiological conditions of the patient

e. Perform nursing implementation for ARI patients

f. Conduct nursing evaluation

\section{2. $\quad$ Attitude and judgment}

Make clinical decisions including diagnoses and plans for nursing interventions to solve problems in ARI cases. 
Table 2. Example of VRS Storyboard in the Case of Nursing Care for Patient ARI for One Learning Objective

\begin{tabular}{|c|c|c|c|c|c|}
\hline No & Learning Objectives & Scences & Actions & Challenges & $\begin{array}{l}\text { Redirect: } \\
\text { FormativeFeedbackFacilitation }\end{array}$ \\
\hline 1 & $\begin{array}{l}\text { Select the appropriate } \\
\text { therapeutic } \\
\text { communication stage }\end{array}$ & $\begin{array}{l}\text { "Place: } \\
\text { emergency } \\
\text { room unit } \\
\text { (ED) for } \\
\text { Puskesmas. } \\
\text { The nurse } \\
\text { meets the } \\
\text { patient in the } \\
\text { ER, the } \\
\text { patientis } \\
\text { seen lying in } \\
\text { the patient's } \\
\text { bed, crying, } \\
\text { short of } \\
\text { breath and } \\
\text { restless, } \\
\text { accompanied } \\
\text { by his } \\
\text { mother } \\
\text { beside him } \\
\end{array}$ & $\begin{array}{l}\text { The nurse must approach the patient, and perform the } \\
\text { stages of therapeutic communication. } \\
\text { If you are close enough to the patient, a choice } \\
\text { balloon will appear, in the form of intrapersonal } \\
\text { communication followed by playback of voice } \\
\text { recordings from each answer option: } \\
\text { Question: What should I do? } \\
\text { A. Say hello (right). Audio: Assalammualaikum, } \\
\text { good morning madam, introduce me to the nurse on } \\
\text { duty on this shift. } \\
\text { B. Inquire about patient complains. Audio what are } \\
\text { the complains that children feel right now? } \\
\text { C. Perform a physical examination. Audio: I checked } \\
\text { the child first. } \\
\text { D. Providing nursing care. Audio: I will take nursing } \\
\text { actions } \\
\text { Select an answer and move using the joystick }\end{array}$ & $\begin{array}{l}\text { The first } \\
\text { time you } \\
\text { meet a } \\
\text { patient, the } \\
\text { nurse must } \\
\text { say hello. } \\
\text { Answer time } \\
\text { limit: } 20 \\
\text { seconds }\end{array}$ & $\begin{array}{l}\text { If the choice is wrong then the } \\
\text { patient will remain restless and turn } \\
\text { away from the nurse } \\
\text { If the answer is correct, a } \\
\text { notification will appear 'Your } \\
\text { answer is correct' and justification } \\
\text { 'first meet the patient must say } \\
\text { hello' and point 100: } \\
\text { Record: the correct answer value }\end{array}$ \\
\hline
\end{tabular}


F. Scenes

Each scene is explained by a written statement and/or an image that is included in the storyboard so that the designer team and VRS developers understand the area and object that the storyboard writer wants to describe. Multi-angle photos of all goods and materials in each room in the health center are provided in the storyboard to provide detailed information to developers when creating 3D assets. For instance, the first scene that displays "Place: Emergency room (ER). The nurse meets the patient in the emergency room, the patient is seen lying in the patient's bed, crying, short of breath and restless, accompanied by his father and mother beside him. The scene table is also equipped with a photo of the bed and emergency room.

\section{G. Action}

Key elements in the preparation of VRS scenarios are problem solving, facilitator response to user actions, and activity progress (Jeffries et al., 2016). The Action column describes activities in a scenario. Actions taken by the user and their interactivity with the scenario. Communication patterns in VRS are designed according to intrapersonal communication patterns. Intrapersonal communication is communication that occurs in oneself that displays discussion in a person's self or mind with himself (Fleischer, Berg, Zimmermann, Wüste, \& Behrens, 2009). For example, when a student will determine a nursing diagnosis, the question will arise: "what is the right nursing diagnosis in this case?" Examples of actions in storyboards are: "The nurse must approach the patient, and perform the stages of therapeutic communication. If you are close enough to the patient will appear choice baloon, in the form of intrapersonal communication followed by the playback of voice recordings of each answer option.

Question: What should I do?
1. Say hello (right). Audio:
Assalammualaikum, good morning, ma'am, introduce me to the nurse on duty at this shift.
2. Inquire about patient complaints. Audio what are the complaints that children feel right now?

3. Perform a physical examination. Audio: I checked the child first

4. Providing nursing care. Audio: I will take nursing actions

\section{H. Challenges}

Part of the "Challenges" describes the conditions in the simulation where the user must act according to the situation presented (Jeffries et al., 2016). The challenge is a tool to assess the mastery of material and clinical skills by giving a reaction to the trigger situation presented. Challenges in this VRS scenario are in the form of questions that challenge students to take appropriate actions, including communicating, taking clinical decisions, assessment techniques, determining nursing diagnoses and conducting nursing interventions. These questions are formative assessment, which is a series of assessments to assess the learning process so that students get feedback and modify their mistakes to improve their understanding (Crooks, n.d.).

Each question will be equipped with a choice of answers where the correct answer will get a reward in the form of 100 points. At the end of VRS the user will get a mean value with a range of 0-100. This assessment feature allows the lecturer to use this VRS session either as a learning exercise activity that is not assessed or summative evaluation which is graded. Another challenge is the time limit where the user is challenged to answer the question correctly with a time pressured pressure of 20 seconds in each question.

\section{Redirection}

According to Jeffries et al., (2016) the response to actions by users and progress in completing activities is very important in designing simulations. Redirection serves to provide good formative feedback and facilitate users during VRS sessions. Feedback or feedback provides crucial information to users when they choose the wrong answer while providing instructions for users to continue completing activities in VRS. Redirection is provided in the form of writing that presents formative feedback and justification of each answer option. Student have three times opportunities or attempts to answer the questions. If the limit of the attempts was 
reached, the correct answer will automatically appear and the participant will get a value of 0 .

\section{J. Debriefing}

Simulation debriefing is a structured and guided reflection process where students actively assess their own cognitive, affective and psychomotor abilities (Sabei\&Lasater, 2016). Debriefing in this VRS is a session provided to review user performance during the VRS session. Data from all challenges, user-generated answers and mean values will be compiled at the end of the VRS session as written feedback. VRS also has a feature to record all sessions with a screen recording system on the monitor screen. Written data and VRS video recordings can be used as debriefing material. Trigger questions for debriefing sessions are developed by a team of experts.

K. Technical support and learning

Support for VRS users include tutorials, learning modules and trial sessions. Tutorials are provided to provide instructions on using VRS including information about navigation and interaction. The recommended learning experience is simplified and structured. Simplified in this scenario is the emergency room that is described as a nurse's work room, so that nursing students are easily oriented to the room. Learning modules are also provided and must be read to prepare students before taking part in VRS. Users must also be provided with VRS trial sessions at the beginning of the course.

\section{DISCUSSIONS}

The VRS is needed by the nursing lecturers as it is a learning method that able to help students achieve the high level of learning outcomes. The expert team highlighted that the VRS functionality should be optimally explored especially in facilitating a high fidelity learning environment, creating experience of how to handle a difficult clinical situations, and allowing experimentations. According to De Gagne, Oh, Kang, Vorderstrasse, and Johnson, (2013), the simulation is effective in training student nursing clinical skills in a safe environment.
The expert team also expects that VRS can be efficient. For example, the scene of thorax auscultation where the users can hear breath sounds when they place the pointer is placed in the correct thorax site, is consider by De Gagne et al., (2013) providing the similar learning experience to SimMan but inexpensive.

The development of the VRS Padjadjaran storyboard technically utilizes the use of intra personal communication in the form of a floating question. It is an interactive tools between the users and him/her-self and their responses to the virtual environment. Intra personal communication allows students to practice critical thinking and reflective on practice (Campbell \& Daley, 2017) to make decisions as a response to the situation. The use of intra personal communication in this case adding a new feature and learning experience to the previous storyboard development by Farra et al., (2016).

The VRS enables the instructional designers to integrate some questions with the level of guided responses (level 3) in Bloom's Taxonomy of psychomotor learning domain that aims to challenge the students to use therapeutic communication skills (Krathwohl, 2002). Each question leads to advanced stages of the thorax examination as cognitive tests. Furthermore, the cognitive skills also are tested in form of haptic or active gesture using a related device to thoracic examination. In cognitive test, user tries to find the correct arrangement in the thorax examination and hear probably the same or different sound according to the point to diagnose ARI cases (Oermann \& Gaberson, 2016).

In accordance with the patient's profile, the nursing assessment in this VRS was prepared based on Integrated Management of Childhood Illness (IMCI). IMCI is a guide to nursing care for under-five years old patients, including respiration problems, especially ARI and Pneumonia (Ministry of Health, 2015). IMCI provides practical guidance for nurses in dealing with sick toddlers by utilizing algorithms or pathways that function to screen and detect diseases, provide guidance for interventions and rapid referrals for sick toddlers (Titaley et al., 2014). In addition, integrating IMCI to the case is a new innovation in VRS utilization in Indonesian nursing education. 
The storyboard also describes the position of the user's eye view over any existing object. This feature superior to the storyboard that developed by Sherry et al. (2016). The combination of questions type and gestures provided also explore more abilities of the user rather than single setting like haptic for skill acquisition such as proposed by Butt, Kardong-Edgren, and Ellertson (2018).However, as a prototype, this VRS Padjadjaran storyboard only cover the case of ARI. It highly potential toimprove the VRS by adding more interaction such as symptoms, sounds and questions, to create different cases with the same context.

\section{CONCLUSIONS}

The Virtual Reality Simulation (VRS) Padjadjaran is prepared in accordance with best practices recommended by the literature to form good learning objects. The VRS storyboard development plays a vital role as a communication medium between scenario designers, Subject Matter Expert (SME) teams, instructional designers, and VR developer teams. The VRS Padjadjaran in a respiratory system disturbance case is expected to provide an immersive virtual experience where students can practice clinical decision-making skills and serves to provide a situation for students to apply basic nursing care skills. The questions were developed by integrating the IMCI guide. The storyboard also uses intrapersonal communication as its communication pattern to train critical thinking and reflective practice to induce awareness in facing a clinical situation. In addition, the assessment featureallows lecturersto utilize the VRS either as a learning exercise activity or a summative evaluation.

\section{REFERENCES}

AIPNI. (2016). Kurikulum Inti PendidikanNers Indonesia 2015. Jakarta: AsosiasiInstitusiPendidikanNers Indonesia (AIPNI).

Alexander, G. L., Pasupathy, K. S., Steege, L. M., Strecker, E. B., \& Carley, K. M. (2014). Multi-disciplinary communication networks for skin risk assessment in nursing homes with high IT sophistication. International Journal of Medical Informatics, 83(8), 581-591. https://doi.org/10.1016/j.ijmedinf.2014.0 5.001

Bamodu, O., \& Ye, X. M. (2013). Virtual reality and virtual reality system components. In Advanced Materials Research (Vol. 765, pp. 1169-1172). Trans Tech Publ.

Beachey, W. (2018). Respiratory care anatomy and physiology: foundations for clinical practice. Elsevier Health Sciences.

Billings, D. M., \& Halstead, J. A. (2015). Teaching in nursing: A guide for faculty. Elsevier Health Sciences.

Blais, K. (2015). Professional nursing practice: Concepts and perspectives. Pearson.

Boore, J., Cook, N., \& Shepherd, A. (2016). Essentials of Anatomy and Physiology for Nursing Practice. Sage.

Bouamrane, M.-M., \&Mair, F. (2014). Integrated Preoperative Care Pathway A Study of a Regional Electronic Implementation. BMC Medical Informatics \& Decision Making, 14(1), 1-32. Retrieved from http://10.0.4.162/1472-6947-1493\%5Cnhttps://login.e.bibl.liu.se/login?u rl=https://search.ebscohost.com/login.asp $\mathrm{x}$ ?direct $=$ true $\& \mathrm{db}=\mathrm{aph} \& \mathrm{AN}=99879881 \&$ site $=$ eds-live $\&$ scope $=$ site

Butcher, H. K., Bulechek, G. M., Dochterman, J. M. M., \& Wagner, C. (2018). Nursing Interventions classification (NIC)-EBook. Elsevier Health Sciences.

Butt, A. L., Kardong-Edgren, S., \& Ellertson, A. (2018). Using Game-Based Virtual Reality with Haptics forSkill Acquisition, Clinical Simulation in Nursing, 16, 2532.

Carretta, P., \& Rice, R. (2016). CAS's New Learning Domains: Using Them in Your Assessment Work. In the meeting of the NASPA International Assessment and Retention Conference. Baltimore.

Davis, R. L. (2009). Exploring possibilities: virtual reality in nursing research. Res Theory NursPract, 23(2), 133-147.

DirjenBelmawaKemenristek-Dikti. (2015). ParadigmaCapaianPembelajaran. DirjenBelmawaKemenristek-Dikti, Republik Indonesia.

Elliman, J., Loizou, M., \&Loizides, F. (2016). Virtual Reality Simulation Training for Student Nurse Education. In Games and 
Virtual Worlds for Serious Applications (VS-Games), 2016 8th International Conference on (pp. 1-2). IEEE.

Fleischer, S., Berg, A., Zimmermann, M., Wüste, K., \& Behrens, J. (2009). Nursepatient interaction and communication: A systematic literature review. Journal of Public Health, 17(5), 339-353.

Foronda, C. L., Alfes, C. M., Dev, P., Kleinheksel, A. J., Nelson, D. A., O’Donnell, J. M., \&Samosky, J. T. (2017). Virtually Nursing: Emerging Technologies in Nursing Education. Nurse Educator, 42(1), 14-17. https://doi.org/10.1097/NNE.000000000 0000295

Gaberson, K., \&Oermann, M. (2010). Clinical teaching strategies in nursing. Springer publishing company.

Gangji, A., \& Hartman, B. (2015). Agile SCRUM For Denver Web Development. Neon Rain Interactive.

Herdman, H. T., \&Kamitsuru, S. (2017). Nursing Diagnoses: Definitions \& Classification 2018-2020. Thieme. Retrieved from https://books.google.co.id/books?id=sJ0u DwAAQBAJ

Huang, H.-M., \&Liaw, S.-S. (2018). An Analysis of Learners' Intentions Toward Virtual Reality Learning Based on Constructivist and Technology Acceptance Approaches. The International Review of Research in Open and Distributed Learning, 19(1).

Jeffries, P. R., \& Jeffries, P. R. (2012). Simulation in nursing education: From conceptualization to evaluation. National League for Nursing.

Jenson, C. E., \& Forsyth, D. M. (2012). Virtual reality simulation: Using threedimensional technology to teach nursing students. CIN - Computers Informatics Nursing, 30(6), 312-318. https://doi.org/10.1097/NXN.0b013e318 24af6ae

Karpicke, J. D., \&Roediger, H. L. (2008). The critical importance of retrieval for learning. Science, 319(5865), 966-968.

Kemenkes RI. (2015). ManajemenTerpaduBalitaSakit (MTBS). Jakarta: Modul, 1-7.

Kolb, A. Y., \& Kolb, D. A. (2012). Experiential learning theory. In Encyclopedia of the Sciences of Learning (pp. 1215-1219). Springer.

LundeHusebø, A. M., \& Storm, M. (2014). Virtual Visits in Home Health Care for Older Adults. The Scientific World Journal. https://doi.org/http://dx.doi.org/10.1155/ 2014/689873

Ma, M., Jain, L. C., \& Anderson, P. (2014). Future trends of virtual, augmented reality, and games for health. In Virtual, Augmented Reality and Serious Games for Healthcare 1 (pp. 1-6). Springer.

Meyer, A. J., Innes, S. I., Stomski, N. J., \&Armson, A. J. (2016). Student performance on practical gross anatomy examinations is not affected by assessment modality. Anatomical Sciences Education, 9(2), 111-120. https://doi.org/10.1002/ase.1542

Moorhead, S., Johnson, M., Maas, M. L., \& Swanson, E. (2018). Nursing Outcomes Classification (NOC)-E-Book: Measurement of Health Outcomes. Elsevier Health Sciences.

Munshi, F., Lababidi, H., \&Alyousef, S. (2015). Low-versus high-fidelity simulations in teaching and assessing clinical skills. Journal of Taibah University Medical Sciences, 10(1), 1215.

Park, C. S.-Y. (2017). The Dark Shadow of Virtual Reality. Journal of Learning and Teaching in Digital Age (JOLTIDA), 3(1), 1-2.

Parsons, L. C. (2014). The birth experience: Learning through clinical simulation. International Journal of Childbirth Education, 29(3), 66.

Parsons, Riva, G., Parsons, S., Mantovani, F., Newbutt, N., Lin, L., Hall, T. (2017). Virtual reality in pediatric psychology. Pediatrics, 140(Supplement 2), S86-S91.

Paulus, E., Suryani, M., Farabi, R., Yulita, I. N., \&Pradana, A. (2016). EVALUASI APLIKASI SEMI-IMMERSIVE VIRTUAL REALITY PADA BIDANG PENDIDIKAN MENURUT ASPEK HEURISTIK DAN PEMBELAJARAN. JIKO (JurnalInformatika Dan Komputer), 1(2).

Sherry, F., Miller, E. T. Hodgson, E., Cosgrove, E., Brady, W., Gneuhs M., \& Baute, B. (2016). Storyboard Development for Virtual Reality Simmulation. Clinical Simmulation in 
Jurnal INJEC Vol. 3 No. 2 December 2018: 121-130

Nursing, 12, 392-399.

Shutterland, J., \& Schwaber, K. (2018). What is Scrum?

Sugiyono.

(2010).

Metodepenelitianpendidikan.

PendekatanKuantitatif.

Titaley, C. R., Jusril, H., Ariawan, I., Soeharno, N., Setiawan, T., \& Weber, M. W. (2014). Challenges to the implementation of the integrated management of childhood illness (IMCI) at community health centres in West Java province, Indonesia. WHO South-East Asia Journal of Public Health, 3(2), 161.

Zacharzuk-Marciano, T. (2017). Nursing faculty experiences of virtual learning environments for teaching clinical reasoning. Capella University. 